\title{
3D resistivity survey for shallow subsurface fault investigations
}

\author{
Kraipat Petrit ${ }^{1}$, Poonnapa Klamthim ${ }^{1}$, and Helmut Duerrast ${ }^{1,2, *}$ \\ ${ }^{1}$ Geophysics Research Center, Prince of Songkla University, 90112 Hatyai, Songkhla, Thailand \\ ${ }^{2}$ Dept. of Physics, Fac. of Science, Prince of Songkla University, 90112 Hatyai, Songkhla, Thailand
}

\begin{abstract}
The shallow subsurface is subject to various human activities, and the place of occurrence of geohazards, e.g. shallow active faults. The identification of the location and orientation of such faults can be vital for infrastructure development. The aim of this study was to develop a lowcost $3 \mathrm{D}$ resistivity survey system, with reasonable survey time for shallow fault investigations. The study area in Songkhla Province, Thailand is located in an old quarry where faults could be identified in outcrops. The study area was designed to cover the expected fault with 100 electrodes arranged in a $10 \times 10$ square grid with an electrode spacing of 3 meters in $\mathrm{x}$ and $\mathrm{y}$ axis. Each electrode in turn was used as a current and potential electrode using a dipole-dipole array. Field data have been processed and interpreted using 3DResINV. Results, presented in horizontal depth slices and vertical xz- and yz-cross sections, revealed through differences in resistivity down to $8 \mathrm{~m}$ depths a complex structural setting with two shallow faults and dipping sedimentary rock layers. In conclusion, this study has shown that a 3D resistivity survey can imagine complex tectonic structures, thus providing a far more insight into the shallow subsurface.
\end{abstract}

\section{Introduction}

The shallow subsurface, the first few hundred meters below the Earth's surface, is subject to various human activities, e.g., building foundations, groundwater drilling, but also the place of occurrence of potential geohazards, e.g., landslides and shallow active faults. The identification of the location and orientation of shallow faults can be vital for infrastructure development, thus mitigating the impact of potential earthquakes. Various types of geophysical methods can be used to identify and locate faults in the shallow subsurface, e.g. 2D resistivity, seismic reflection, and ground penetrating radar; however these techniques produce only a $2 \mathrm{D}$ cross section of the subsurface. In order to get more information about a more complex subsurface either several $2 \mathrm{D}$ surveys have to be conducted or real 3D ones. Among the latter ones is the 3D resistivity method. It is a relatively fast and easy method to do in comparison to a real $3 \mathrm{D}$ seismic reflection survey, which is commonly applied in petroleum exploration and deeper depths.

\footnotetext{
*Corresponding author: helmut.j@psu.ac.th
} 
The objective of this work is to develop a fully functioning system for $3 \mathrm{D}$ resistivity measurements using the available technology at the department and then testing the system and subsequent data processing and interpretation for a study site where the subsurface structures were known from geological field observations.

\section{Theories}

\subsection{Resistivity of rock and material}

Resistivity of a material is defined as the resistance in ohms between the opposite face of a unit cube of material. For a cylinder of resistance $\delta \mathrm{R}$, length $\delta \mathrm{L}$, and cross-section area $\delta \mathrm{A}$, the resistivity $\rho$ is given by equation 1 with resistivity is ohm-meter [1].

$$
\rho=(\delta R \delta A) / \delta L
$$

Resistivity is one of the physical properties with the largest variation (Fig. 1). Metallic minerals in igneous rocks, for example, conduct electrical currents by their free electrons. For porous sediments and sedimentary rocks, which make up most of the shallow subsurface, the electrical current is carried by ions in the pore fluid; thus the resistivity of shallow subsurface materials depend mainly on the type of pore fluid, saturation, and porosity. This process is called electrolytic conductivity. Resistivity for this kind of material is defined by equation 2, Archie's law [1,2],

$$
\rho=\left(a \rho_{w}\right) /\left(S_{w}{ }^{n} \emptyset^{m}\right)
$$

where $a$ is a constant, $\rho_{w}$ is the resistivity of the pore fluid, $S_{w}$ is the water saturation, $n$ is saturation exponent, $\varnothing$ is the porosity, and $m$ is the cementation exponent.

For clay material the situation is different as their surface is electrical charged resulting in colloidal conductivity. Therefore, resistivity values for clay are usually very low (see Fig. 1).

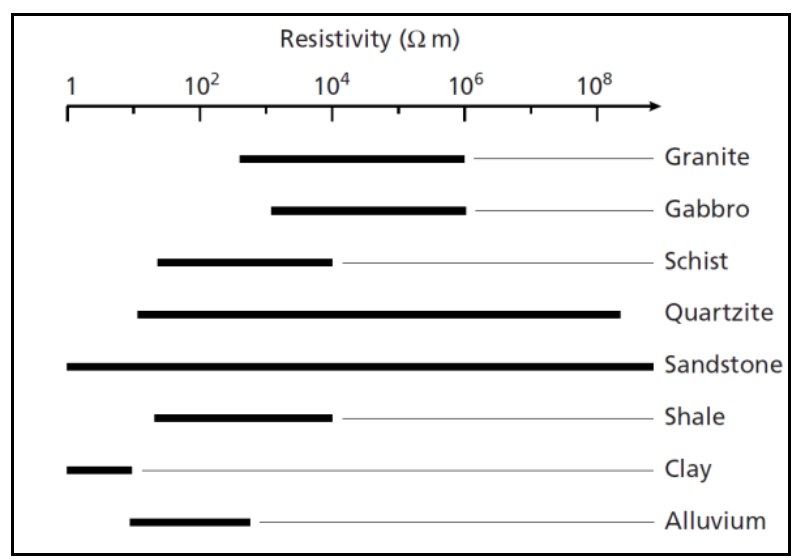

Fig. 1. Resistivity range of some common rock and sediment types, after [2].

Porosity is one of the most important rock properties in describing porous media. It is defined as the ratio of pore volume to bulk volume of a rock sample. This factor is a dimensionless quantity, expressed either in decimal or percentage. Fluid inside the pores of the shallow subsurface is mainly water and air [3]. The permeability of a rock is a measure 
of the ease with which the rock will permit the passage of fluids. If fluid passes through the rock easily, it has high permeability, and opposite.

\subsection{Resistivity survey}

Resistivity survey is one type of geophysics method wildly used for shallow subsurface investigations. Here, a source current is injected into the subsurface via two electrodes, with the resulting potential of the subsurface measured by two other electrodes [2]. Measured values of this method are 'apparent resistivity' values, which are calculated from the current, potential, and distance arrangement of the electrodes as shown in equation 3 $[2]$,

$$
\rho_{a}=k(\Delta V / I)=k R
$$

where $\rho_{a}$ is the apparent resistivity, $R$ is the resistance measured with a resistivity meter and $k$ is the geometric factor, which depends on the overall arrangement and distance of the four current and potential electrodes.

A 3D resistivity survey is used to study the resistivity distribution in three dimensions; $x, y$ and $z$ (depth) dimension. Generally, electrodes are set on the ground surface of the study area in a rectangular or square grid. All electrodes are connected to a resistivity meter and also used to inject electrical current as well as to measure the potential [4].

\subsection{Inversion method}

Inversion method is used to estimate a possible physical model of the subsurface structure from the observed data. In this case, the observed data are apparent resistivity values from field survey and the model parameter are 'true' resistivity values of the subsurface. 3DResINV is available resistivity inversion software, which is used in this work. Inversion routine is based on the smoothness-constrained least-square method shown in equation 4 . Procedures of this software make rectangular blocks where the model resistivity values are allowed to vary in all three directions; then try to reduce the difference between calculated data and measured apparent resistivity values by adjusting the resistivity of the model blocks. A measure of this difference is given by the root-mean-square (RMS) error [4, 5].

$$
\left(J^{T} J+\lambda F\right) \Delta \boldsymbol{q}_{\boldsymbol{k}}=J^{T} g-\lambda F \boldsymbol{q}_{\boldsymbol{k}}
$$

where $J$ is the Jacobian matrix of the partial derivative, $J^{T}$ is the transpose of $J$, $\lambda$ is a damping factor, $q_{k}$ is the model perturbation vector, $g$ is a misfit data, and $F$ is a roughness filter.

\section{Field survey}

\subsection{Study area}

The study area was in an old quarry located in the northern part of Sadao district, Songkhla province, Southern Thailand (Fig. 2a). The northern part is a flat area because rocks and soils have been taken out. In the southern part still remained the part of a hill and sediment layer can be seen from cliffs marking the quarry boundary. All formations in the quarry are sedimentary rocks with conglomerates, conglomeratic sandstone, and sandstone. In some parts of the area sandstone interbedded with siltstone occurred (Fig. 2b and 3). 




Fig. 2. Study area: (a) Location of study area in northern part of Sadao district, Songkhla province, southern Thailand, (b) Boundaries of the survey area with the direction of the $\mathrm{x}$-axis 50 degrees from north over west, (c) Square grid of $10 \times 10$ electrodes with $x-, y$ - and z-direction, and (d) Equipment set up consisting of resistivity meter, $12 \mathrm{~V}$ battery, switch box, and cable assembly.

\subsection{Structural geology}

Structural geological surface investigations in the study area revealed dipping sedimentary layers and faults (Fig. 3). Fig. 3d shows sediment layers dipping into north-west direction (288, dip direction) with dip angles of 15-20 degrees. The upper layer is conglomerate and the lower layer is sandstone and siltstone. Fig. $3 \mathrm{a}$ and $3 \mathrm{e}$ show a fault that can be found in this area. Measurements of the fault plane show that the fault is dipping into south direction with a dip angle of 64 degrees (dip direction/dip angle, 222/64).

\subsection{Data acquisition and processing}

To prove that $3 \mathrm{D}$ resistivity survey can be used to determine the structure of the subsurface, the study area is designed to cover the expected fault line show in Fig. 3. From Fig. 2b and $2 c$, the study area is a square grid of $x$ - and y-axis. Direction of $x$-axis is 50 degree from north over west. Fig. 4 shows that 100 electrodes are set in a square grid with an inline spacing of $3 \mathrm{~m}$ for both $\mathrm{x}-$ and $\mathrm{y}$-axis. Therefore, the size of the study area is $10 \times 10$ electrodes with $27 \times 27 \mathrm{~m}$ (Fig. $4 \mathrm{c}$ ).

Electrode configuration used to determine resistivity values in this work is dipoledipole array; it consists of one of current electrode pair and one of potential electrode pair, show in Fig. 4 b. From the $10 \times 10$ square of electrodes, 840 values of apparent resistivity have been measured from all directions; 10 lines in x-direction, 10 lines in y-direction, and 26 lines in both diagonal directions. 

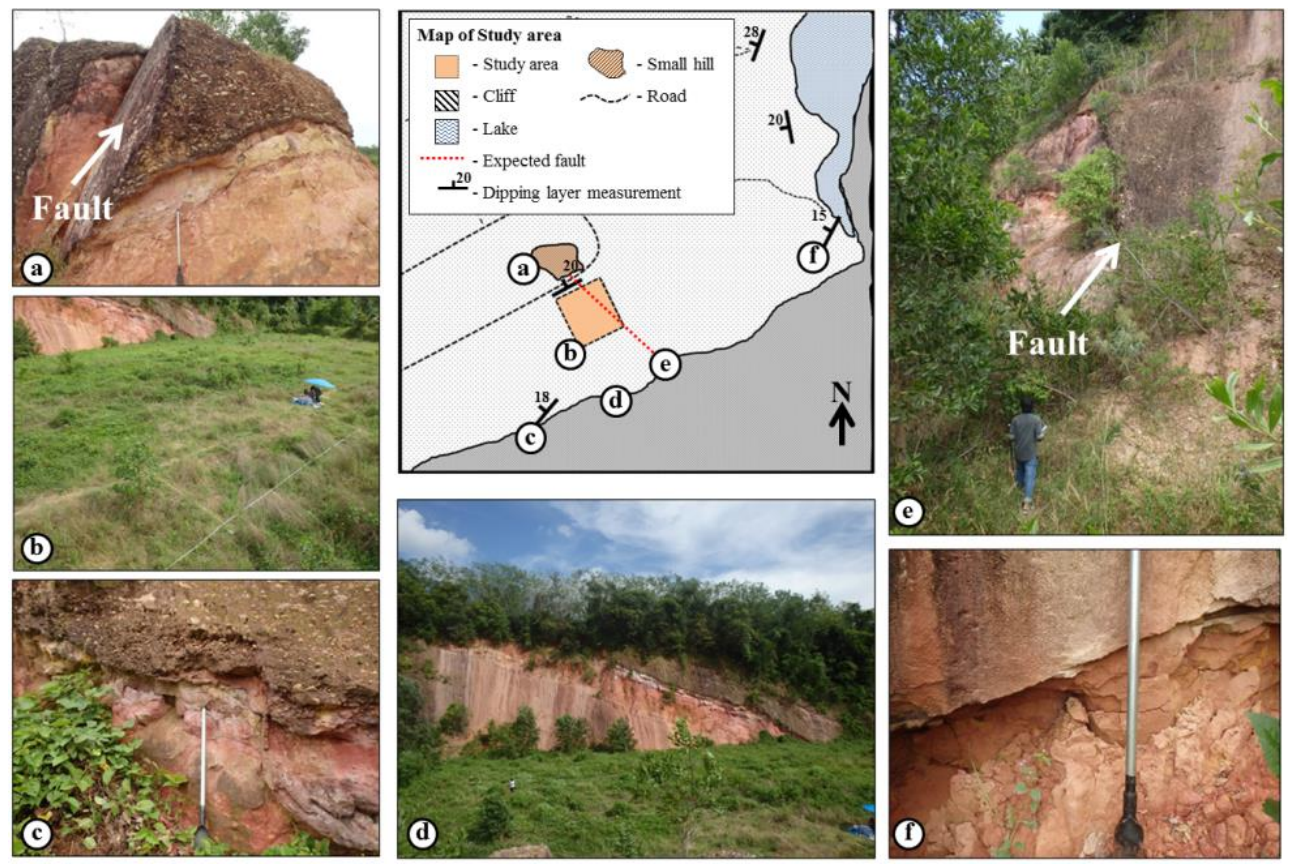

Fig. 3. Structural geology of study area (a) Fault, looking into NW, dip direction/dip angle of the fault plane is 222/64 and of the sedimentary layering 333/20, (b) Study area, looking into SE, (c) Sedimentary layer in the quarry nearby the study area, looking into SE, and measurement of sedimentary layering is $310 / 18$, (d) Sedimentary layering seen at the cliff locate in the southern part of the study area, (e) Fault, looking into SE, with an orientation of 222/64, and (f) Sedimentary layering near the study area, looking into NW; measurement of layering plane gives 288/15.
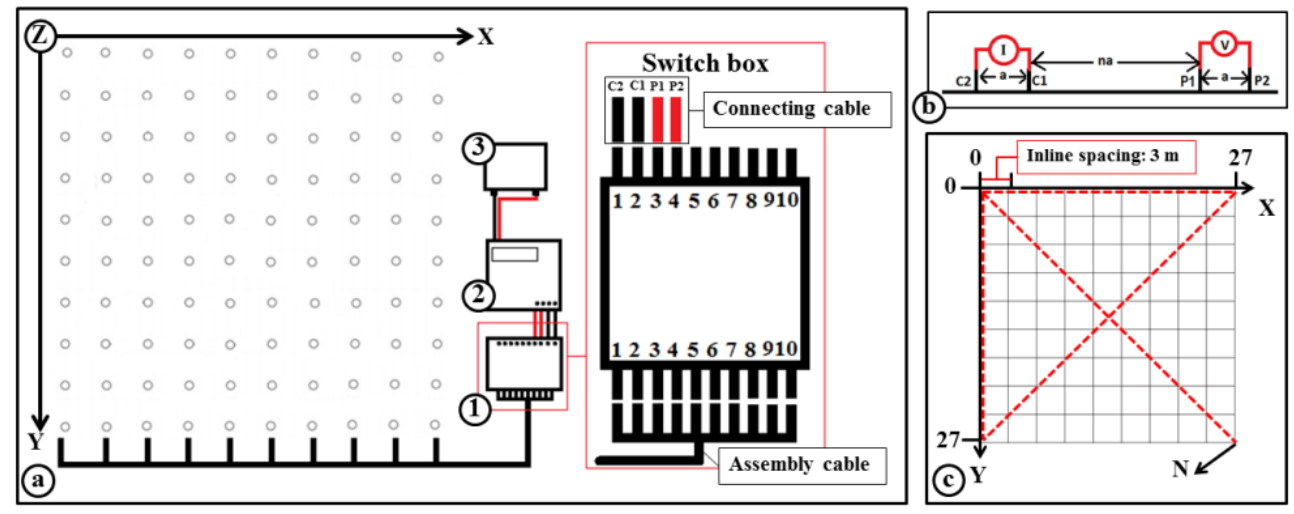

Fig. 4. Survey design and equipment: (a) Diagram of equipment set up consisting of 100 electrodes arranged in a $10 \times 10$ square grid, cable, switch box (1), resistivity meter (2) and $12 \mathrm{~V}$ battery (3), (b) Arrangement of electrodes in dipole-dipole array, C1-C2 is current electrode pair, P1-P2 is potential electrode pair, a is $3 \mathrm{~m}$ inline spacing and $\mathrm{n}$ is the ratio varied from 1 to 7 for 10 nodes of electrodes, and (c) Measurement lines, $\mathrm{x}, \mathrm{y}$, and both diagonal directions.

Equipment used to measure the apparent resistivity values is a Terrameter SAS 1000, single-channel resistivity meter. The main difference from a multi-channel resistivity meter that is actually used for a $3 \mathrm{D}$ resistivity survey is the limitation of a single-channel. Therefore, the resistivity meter cannot measure more than one data point at the same time 
of injecting current. In this work, a switch box was developed to use with a single-channel resistivity meter. Fig. 4a shows a diagram of the equipment set up with 10 electrodes in one line connected to the switch box by a cable assembly. The switch box is connected to the single-channel resistivity meter by two pairs of cables; a current cable pair and a potential cable pair. By this way, all data points in one line can be measured by moving the current cable pair and the potential cable pair on the switch box.

After data acquisition, the 3DResINV software processes the apparent resistivity values. Results from the software are images of resistivity distribution in horizontal sections ( $x y$ plane), $\mathrm{x}$-sections ( $x z$ plane), and y-sections ( $y z$ plane).

\section{Results and discussions}

Fig. 5 and 6 present the inversion results of the resistivity model of the study area. From these results resistivity areas can be separated in two zones: A low resistivity (L) area with resistivity values varying from 10 to $2,000 \mathrm{ohm} \mathrm{m}$, indicated by blue and green colors; and a higher resistivity area $(\mathrm{H})$ that has a resistivity range of 2,000 to 5,000 $\mathrm{ohm} \mathrm{m}$, indicated by red and purple colors.

Including the geological information, low resistivity area can be considered to be siltstone and sandstone, whereas the high resistivity areas can be considered to be conglomerate. As the porosity and permeability of the conglomerate is lower than siltstone and sandstone, the resistivity of the conglomerate is higher than of the siltstone and sandstone.

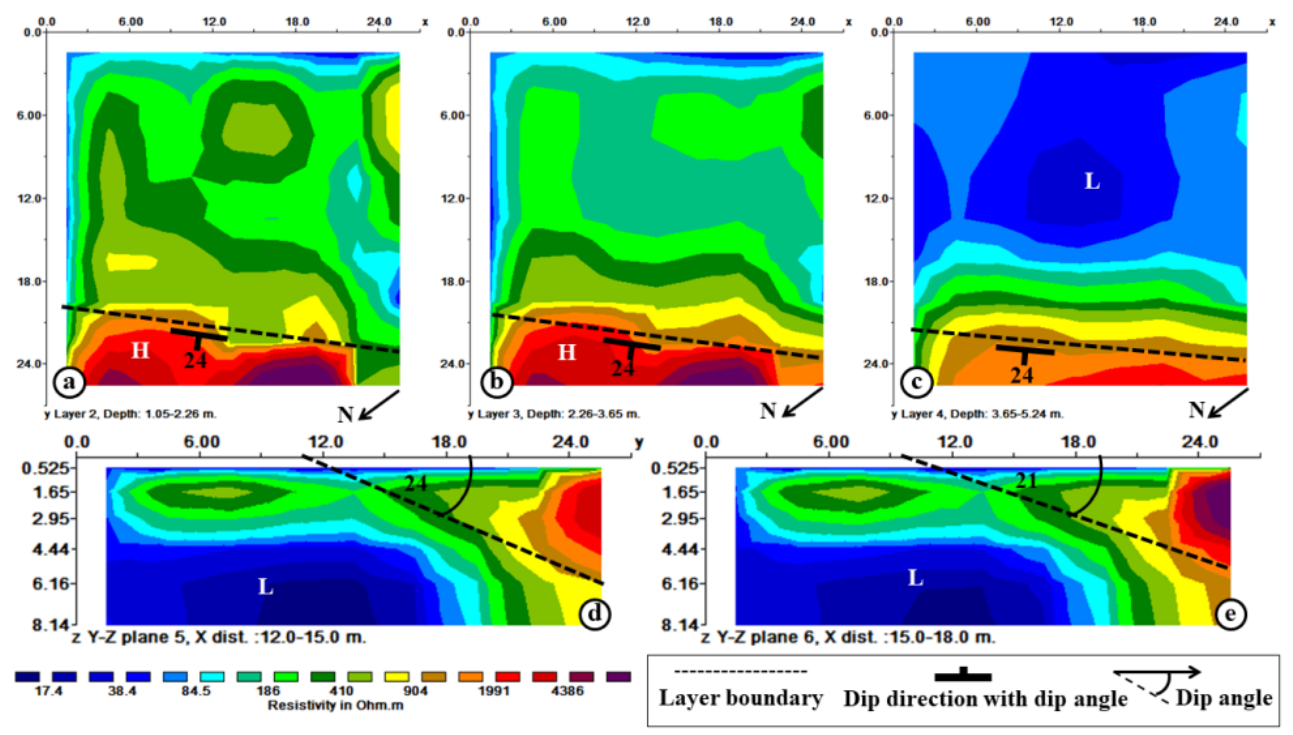

Fig. 5. Structural geology discussion, sedimentary layering: (a), (b), and (c), results of resistivity model in horizontal section of difference depth intervals with an interpretation of dip direction of the sedimentary layers, and (d) and (e) results of resistivity model in y-section with interpretation of dip angle of the layers. $\mathrm{L}=$ low resistivity, $\mathrm{H}=$ high resistivity. 


\subsection{Dipping sedimentary layers}

Fig. 5a-c presents the resistivity models of the horizontal sections for different depth intervals. Results show that layers of higher resistivity indicated to be conglomerate layers dipping into northwest direction, 225-230 degrees from north. From Fig. 5d and 5e, the dip angle is $20-25$ degrees from the surface.

\subsection{Faults}

The consideration of fault lines in this area is based on discontinuity of resistivity values. As faults are cracks in the subsurface that can separate sedimentary layers they create discontinuities in the resistivity values. Fig. 6 shows that there are two fault lines in the study area; Fault 1 dipping into south direction, with a dip direction of 210 degrees from north and a dip angle of 68 degrees. Fault 2 is dipping in south direction with a dip direction of 215-220 degrees from north and a dip angle of 74 degrees.
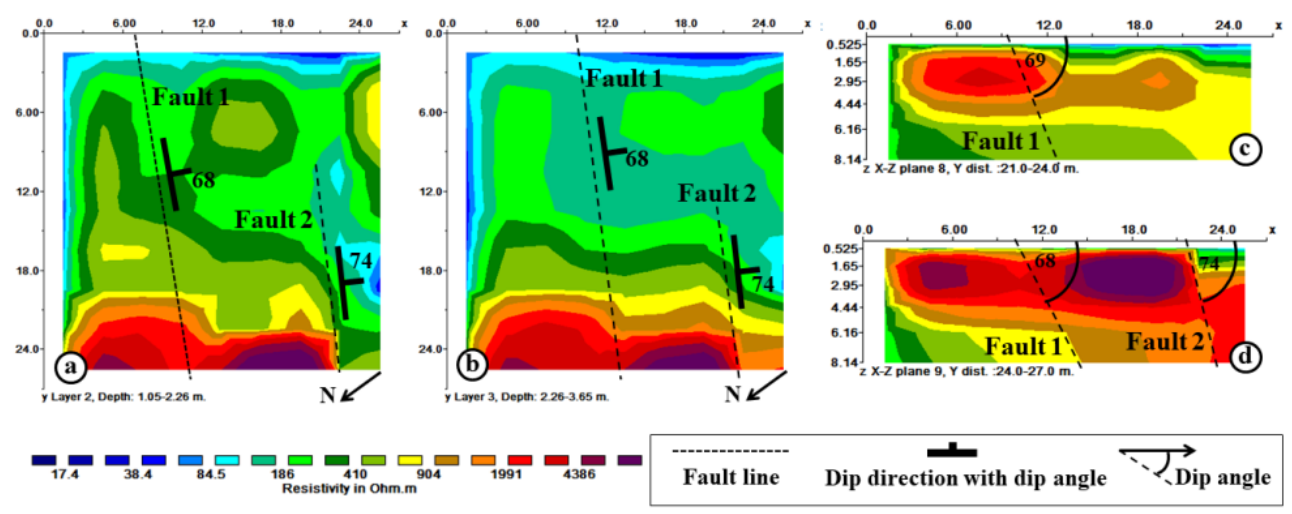

Fig. 6. Structural geology discussion, faults: (a) and (b) results of resistivity model in horizontal section with interpretation of dip direction of faults, and (c) and (d) results of resistivity model in $\mathrm{x}$ section with interpretation of dip angle of the faults. $\mathrm{L}=$ low resistivity, $\mathrm{H}=$ high resistivity.

\section{Conclusions}

\subsection{Subsurface model}

From the resistivity survey, the result shows that the sedimentary layers dipping into northwest direction with a dip angle 20-25 degrees. Information of dipping sedimentary layers correlates with the geology data (see Fig. 3). The upper layer with higher resistivity should be conglomerate and the lower layer with lower resistivity should be siltstone and sandstone, as shown in Fig. 7.

From geological data, Fault 1 correlates with the expected fault line because both have similar dip direction and dip angle. From the results Fault 2 cannot be seen and identified from the surface. Detecting Fault 2 proves that a 3D resistivity survey can be used to determine geological structures in the subsurface that cannot be seen from surface investigations. 


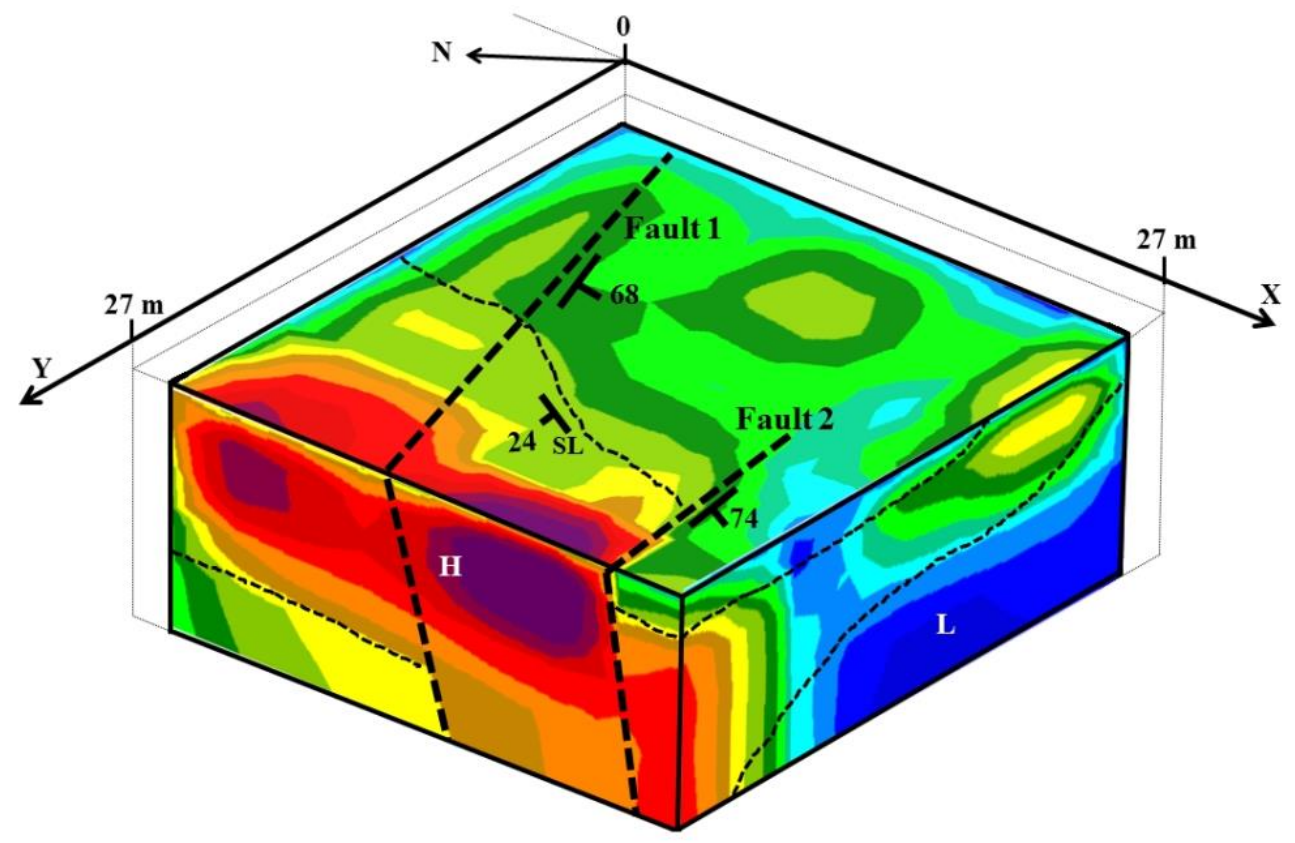

Fig. 7. Subsurface model from 3D resistivity survey: Fault information; Fault 1 is dipping into south direction with 68 degrees dip angle and Fault 2 is dipping into south direction with 74 degrees dip angle. Sedimentary layering (SL) shows dipping into northwest direction with a dip angle of 24 degrees. $\mathrm{L}=$ low resistivity, $\mathrm{H}=$ high resistivity.

\subsection{Acquisition system}

Conclusion also can be drawn regarding the 3D resistivity acquisition system. Results presented here show that it is possible to make a 3D resistivity survey by using a singlechannel resistivity meter with a switch box and cable assembly instead of a multi-channel resistivity meter that still requires high survey costs nowadays. From this work, the data acquisition system can measure 840 data points in one to two days depending on survey area environment and the survey costs are actually lower than using a multi-channel resistivity meter.

\section{References}

1. P. Kearey, M. Brooks, I. Hill, Introduction to Geophysical Exploration, $3^{\text {rd }}$ ed. (Blackwell Science Ltd, Oxford, 2002)

2. W.M. Telford, L.P. Geldart, R.E. Sheriff, Applied Geophysics, $2^{\text {nd }}$ ed. (Cambridge University Press, New York, 1990)

3. R. Bowen, Groundwater, $2^{\text {nd }}$ ed. (Elsevier Applied Science Publisher, Essex, 1986)

4. M.H. Loke, Tutorial: 2-D and 3-D electrical imaging surveys (2015)

5. M.K. Sen, P.L. Stoffa, Globle Optimization Methods in Geophysics Inversion, $2^{\text {nd }}$ ed. (Cambridge University Press, New York, 2013) 